\section{P6.027 FACTORS ASSOCIATED WITH USE OF WATER-BASED LUBRICANTS BY MEN WHO HAVE SEX WITH MEN: FINDINGS FROM A BIO-BEHAVIOURAL STUDY IN THREE INDIAN STATES}

doi:10.1136/sextrans-2013-051184.1181

'S Ramanathan, ${ }^{2} \mathrm{~V}$ Chakrapani, 'L Ramakrishnan, 'P Goswami, 'D Yadav, 'B George, 'S Sen, ${ }^{3} \mathrm{R}$ Paranjape, ${ }^{4} \mathrm{~T}$ Subramanian, ${ }^{5} \mathrm{H}$ Rachakulla. ${ }^{1} \mathrm{FHI}$ 360, New Delhi, India; ${ }^{2}$ Centre for Sexuality and Health Research and Policy (C-SHaRP), Chennai, India; ${ }^{3}$ National AIDS Research Institute (NARI), Pune, India; ${ }^{N}$ National Institute of Epidemiology (NIE), Chennai, India; ${ }^{5}$ National Institute of Nutrition (NIN), Hyderabad, India

Background Unprotected anal sex among men who have sex with men (MSM) has a high probability of transmission of HIV, but using water-based lubricants along with condoms can significantly reduce HIV risk. We examined the prevalence and type of rectal lubricants use, and factors associated with exclusive use of waterbased lubricants among MSM using data from a large-scale crosssectional survey conducted in 2009-2010 in three Indian states.

Methods Using time-location cluster sampling, 3,880 MSM were recruited from cruising sites such as parks and local train stations. Behavioral data were collected using a structured questionnaire, and blood and urine samples were tested for HIV and STIs. We used binary logistic regression to assess the association between type of lubricants used and socio-demographic and programmatic indicators.

Results Of the total, a majority reported using lubricants (64\%) and more than half (53\%) exclusively used water-based lubricants. Less than one-tenth (7.6\%) reported exclusive use of oil-based lubricants and nearly $40 \%$ of the MSM were mixed users (using both water and oil-based lubricants). Characteristics associated with increased odds for exclusive use of water-based lubricants taking non-users as reference were: exposure to HIV prevention interventions (AOR: 6.18, 95\% CI 4.82-7.92), self-identity as kothis (AOR: 2.56, 95\% CI 2.12-3.10), and consumption of alcohol (AOR: 1.28, $95 \%$ CI 1.07-1.53). When adjusted for socio-demographic and other contextual factors such as exposure and consumption of alcohol, HIV and STI prevalence did not have a statistically significant association.

Conclusion Targeted HIV interventions among MSM need to promote and distribute condom-compatible lubricants during anal sex and educate them not to use oil-based lubricants with condoms. Reaching and promoting condom-compatible lubricant use among all subgroups of MSM, irrespective of their presumed or stated sexual role in anal sex, will help in increasing the use of lubricants during anal sex and decreasing HIV transmission.

\section{P6.028 MULTI-SECTORAL RESPONSE TO PREVENT HIV/AIDS AND STI AMONG SEX WORKERS: AN EXPERIENCE FROM BANGLADESH}

doi:10.1136/sextrans-2013-051184.1182

S Islam. Padakhep Manabik Unnayan Kendra, Dhaka, Bangladesh

Background To create a supportive environment and ensure smooth implementation of HIV/AIDS and STI prevention programme among hotel based sex worker's in Chittagong, Bangladesh a Project Facilitation Team (PFT) was formed in 2005.

Methods The members of the Project Facilitation Team was selected as representatives from hotel management, the department of police, public prosecutors, department of health, media professionals, department of women affairs, social leaders, Muslim religious leader and members from other NGO working in the city. Results The PFT has been seating quarterly basis to review programme progress. They are cooperating to reduce barriers of service delivery and mobilising social support for project activities take place. They have been facilitating regular contact with key stakeholders, including sex workers, member of law enforcement agencies and hotel management. As a result police is not harassing our Peer Educator and they are allowing them to conduct Behavior Change Communication (BCC) session at hotel and the hotel owner/hotel management has been giving the free access to work with the sex worker in their hotel. The Muslim religious leader has been giving speech on HIV/AIDS during the weekly prayer. Media has been publishing positive news/article on HIV/AIDS issue on regular basis. Public Prosecutors have been working with police in handling case related to the sex worker in the court. As a result, the programme has been implementing smoothly in the city and the targeted participants have been receiving comprehensive service i.e. BCC information, STI management service, condom and lubricant, VCT, general and psycho sexual counselling from the project.

Conclusion The members of PFT can support the project's implementation with their local knowledge and influence. So, it can be a best model for other countries.

\section{P6.029 ANTIRETROVIRAL THERAPY (ART) PROGRAMME IN BANGLADESH: INCREASING NATIONAL OWNERSHIP}

doi:10.1136/sextrans-2013-051184.1183

M S Islam, S Rasin, L Rahman. Save the Children, Dhaka, Bangladesh

Background The first HIV positive case was detected back in 1989. From then 2,871 cases have been reported till December 2012 However, the estimated number of PLHIV in Bangladesh is 7,500. Most of the HIV programme for last decades has been focused on HIV prevention. In 2005, ART programme was started in NGO settings in a small scale. Under the Global Fund Round 6 project, Ministry of Health and Family Welfare (MOHFW)/National AIDS/STD Programme (NASP) as Principal Recipient (PR) and Save the children as Management Agency (MA) initiated ART programme for PLHIV (People living with HIV/AIDS).

Methods Enormous efforts of Save the Children, as PR, through active formal and informal co-ordination and advocacy with NASP, UNAIDS, UNICEF, and other relevant stakeholders, ARV drug distribution process has been taken over by the government in December 2012.

Results Before 2008, 100\% of ART was managed by INGOs and their implementing partners in the country. Central Medical Stores Depot of MOHFW has started ARV procurement in 2012. Before that, Save the Children has provided ART to 911 PLHIV in past 4 years with grants from the Global Fund. Beginning of 2013, $88.28 \%$ of PLHIV were provided ARV through Public-Private Partnerships (PPP). To provide direction to the national ART programme, MOHFW developed ART guidelines (2006, updated in 2011), Management of Opportunistic Infection (2009) and also developed Standard Operating Procedures (SOP) for Services to PLHIV in 2009. Simultaneously NASP installed CD 4 counters and additional laboratory equipment in eight tertiary government health institutes for HIV management. Conclusion Nevertheless challenges remain. Government health system is yet to be sensitised and ready to start full-scale ART. An effort is ongoing to establish an efficient ARV drug procurement, supply chain system and PLHIV-friendly distribution mechanism in government-managed health facilities.

P6.030 PHYSICAL EXERCISES FOR PEOPLE LIVING WITH HIV
AND AIDS (PLHIV): BRAZILIAN POLICY FOR POSITIVE
PREVENTION IN THE PUBLIC HEALTH SYSTEM

doi:10.1136/sextrans-2013-051184.1184

K C Abreu, M A Freitas. Ministry of Health of Brazil, Brasilia, Brazil

Background Physical exercise strategies were included in Brazilian AIDS Program actions on positive prevention for PLHIV in 2010, to prevent side effects and improve adherence. A multiprofessional 